\title{
Assessing the Sensitivity of Ecosystem Services to Changing Pressures
}

Tara Hooper ${ }^{\mathrm{a} *}$, Nicola Beaumont ${ }^{\mathrm{a}}$, Charly Griffiths ${ }^{\mathrm{b}}$, Olivia Langmead ${ }^{\mathrm{b}, \mathrm{c}}$ and Paul J. Somerfield ${ }^{\mathrm{a}}$

${ }^{a}$ Plymouth Marine Laboratory, Prospect Place, The Hoe, Plymouth, PL1 3DH, UK

${ }^{\mathrm{b}}$ The Marine Biological Association, Citadel Hill, Plymouth PL1 2PB, UK

${ }^{\mathrm{c}}$ The Marine Institute, Plymouth University, Drake Circus, Plymouth, PL4 8AA, UK

*Corresponding author. E-mail address: tarh@pml.ac.uk

\begin{abstract}
The ecosystem services approach is widely recognised as a concept, but more attention must be given to the development of tools to facilitate practical implementation if the approach is to become more widely used to support decision-making. A key component of natural resource management is understanding the implications of changing levels of pressures on ecosystem components, which is achieved through sensitivity assessment. This paper examines how sensitivity assessment could be applied to ecosystem services, as opposed to the underlying habitats and species, by considering the relationship between the sensitivity of a service to the sensitivity of the habitat responsible for its supply. The method is illustrated using a UK case study of supporting and regulating services provided by subtidal sedimentary habitats within the UNESCO Biosphere Reserve in North Devon.
\end{abstract}

\section{Keywords}

Ecosystem services; Sensitivity assessment; Subtidal sedimentary habitats;

\section{Introduction}

The assessment and valuation of ecosystem services (ES) is widely advocated as a tool to support natural resource management in situations ranging from natural capital accounting (NCC, 2014) to marine planning (Börger et al., 2014). To date, much effort has been focused on the development of conceptual frameworks, but increasing the use of ES assessment in decision-making requires further examples that demonstrate techniques for practical application in a management context. A case in point is that conceptual frameworks recognise that pressures (impacts on the environment from human activity) affect ES delivery (e.g. TEEB 2010; UKNEA 2011; MAES, 2013). However, little attention has been given to developing tools to understand how changing levels of pressure may enhance or diminish the delivery of services and benefits in real terms. 
Techniques already exist within natural resource management that have the potential to be adapted for use in determining the relationship between changing pressures and ES supply. Sensitivity assessments involve the collation of existing information on key characteristics of a species or habitat and its response to environmental change, and the presentation of this information in a format that is accessible to decision makers (Hiscock and Tyler-Waters, 2006). They have been applied in a variety of contexts including: identifying species and habitats in need of protection (OSPAR, 2003); supporting the selection of Marine Protected Areas (Tillin et al., 2010); in marine planning (MMO, 2012); and as part of the Environmental Impact Assessments of coastal developments such as marina construction (ABPmer, 2010).

This paper extends the concept of sensitivity assessment to consider the sensitivity of specific ES to pressures, rather than the underlying habitats and species. An approach for assessing the sensitivity of ES to pressures at the local scale is proposed, utilising available information on i) the sensitivity of these habitats to certain pressures, and ii) the ecosystem services provided by particular habitats. We trial this novel and generic methodology in a case study of the marine transition zone of the UNESCO Man and Biosphere Reserve in North Devon, demonstrating its application as a tool to assess the risk to ES posed by different pressures.

\section{Method}

\subsection{General approach}

Sensitivity assessments have been carried out for different species and habitats in a range of contexts (e.g. Mainwaring et al., 2014; Pecl et al., 2014). As ES delivery can be linked to habitat or species type (e.g. Potts et al., 2014) existing information and sensitivity assessments for those species or habitats are an appropriate starting point for the assessment of ES sensitivity. These assessments can be combined to provide an insight into the sensitivity of ES to specific pressures at a given site. This overarching framework (Figure 1) was applied in the North Devon Biosphere Reserve (NDBR) case study site (Figure 2). 


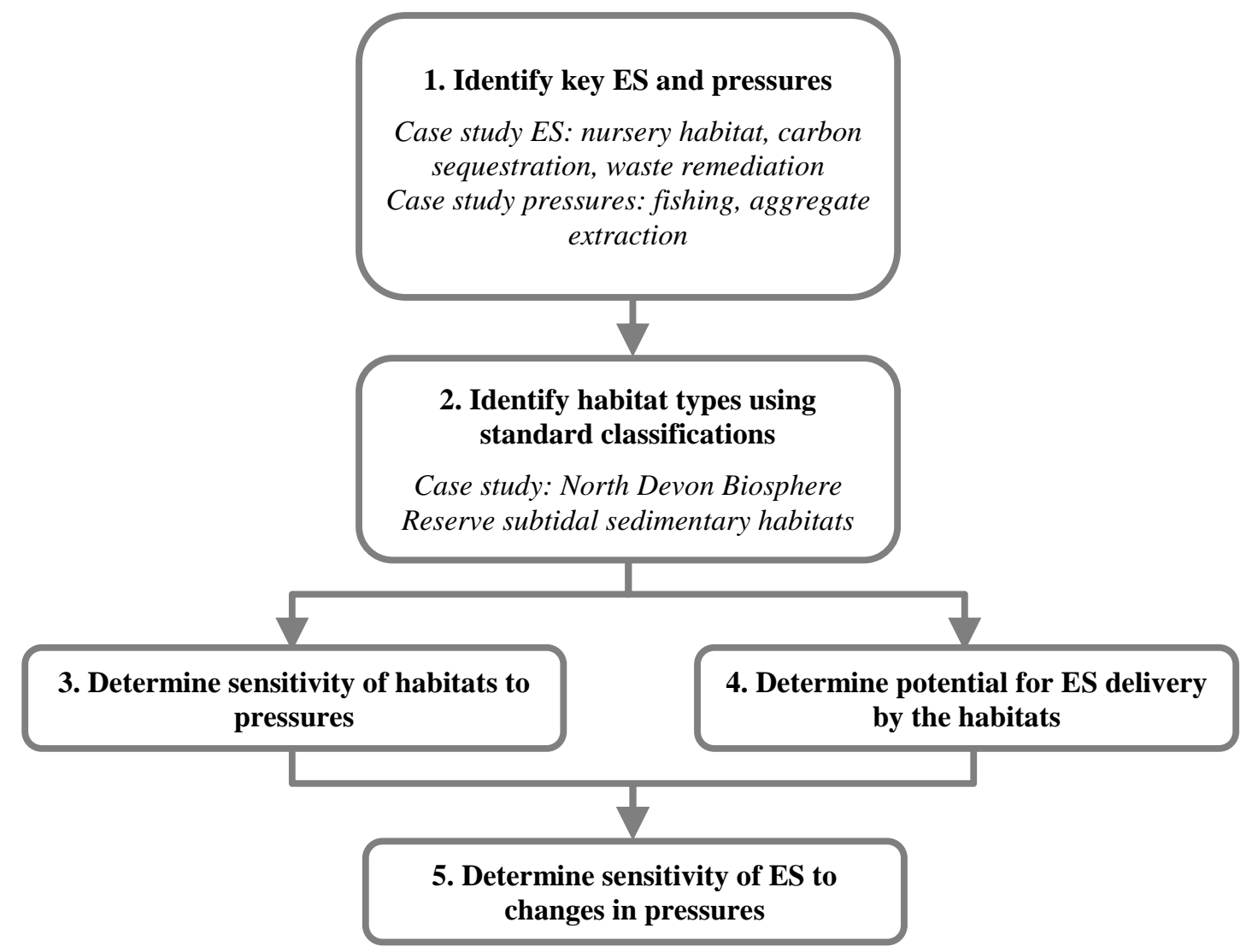

Figure 1. A schematic for the process of combining knowledge of ecosystem services (ES) delivered by particular habitats with habitat sensitivity assessment to allow the sensitivity of ES to be determined, including the examples provided by the case study

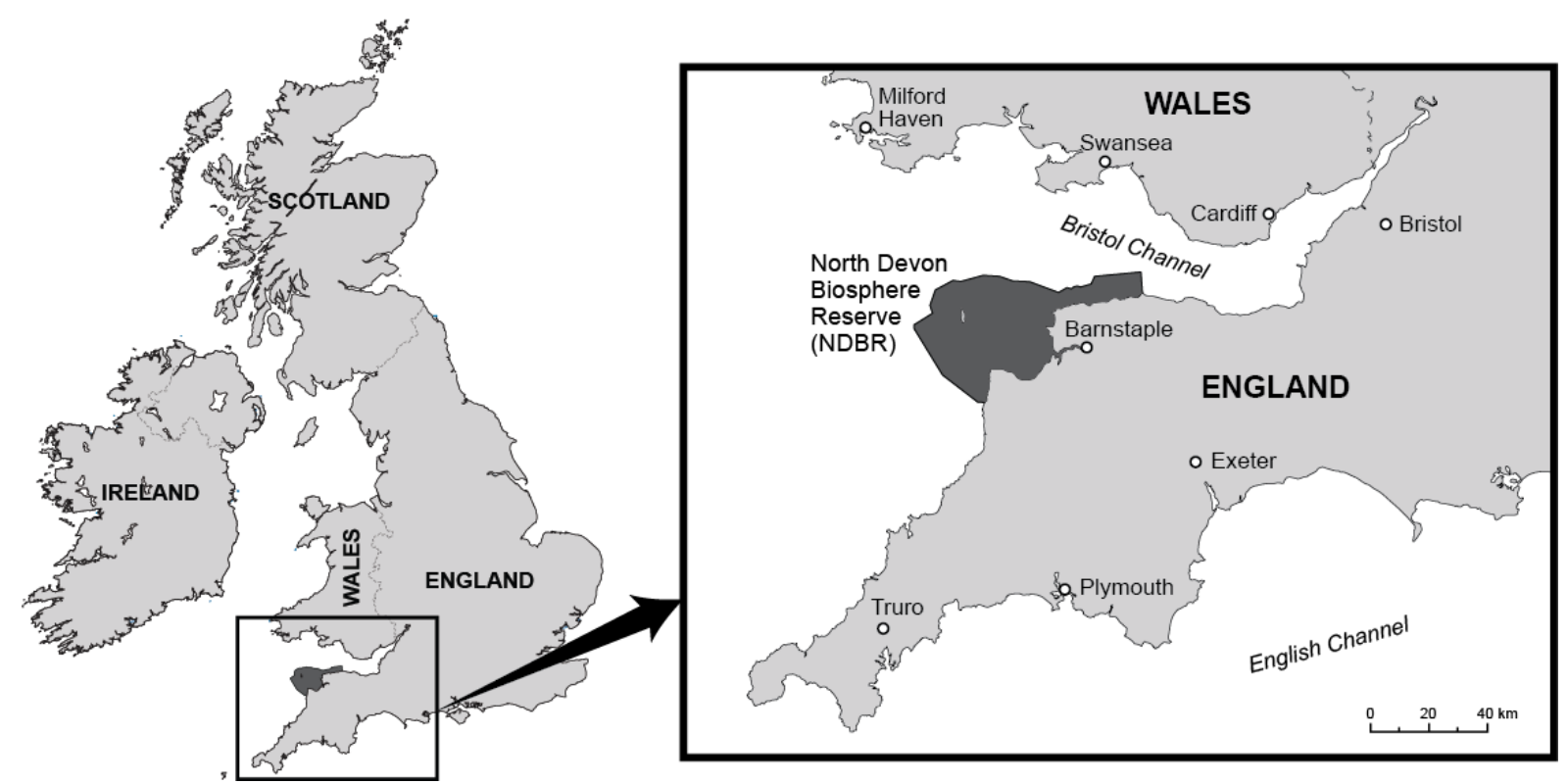

Figure 2. Location of the marine transition zone of the North Devon Biosphere Reserve 


\subsection{Identify key ES and management issues (Step 1)}

Stakeholders were consulted to determine which management issues and ES were considered of greatest importance through questionnaires with representatives of different marine interest groups identified through the NDBR Marine Working Group (Pendleton et al. 2015). The study was framed around local concerns to ensure the outputs would be of practical use and had management relevance, and also to increase local ownership of the research. Subsequently, scenarios were developed with the stakeholders during a series of workshops to identify potential future management options for the NDBR, which would potentially impact on these ecosystem services (Langmead et al., 2015) and these became the focus for application of the proposed methodology.

\subsection{Identify habitat types using standard classifications (Step 2)}

The subtidal sedimentary habitats present within the NDBR were determined using benthic survey data where this was available (RWE npower, 2011; Mackie et al, 2006; Warwick and Davies, 1977; North Devon Council, unpublished data), supplemented with predicted habitats derived during the Mapping European Seabed Habitats (MESH) and UKSeaMap projects (JNCC 2010, 2013). The habitats were described using European Nature Information System (EUNIS) codes to ensure they were identified in a standard way that would facilitate the use of existing sensitivity assessments, with the codes used recognising the resolution of the underlying data. The habitats were mapped using ArcGIS 10.1.

\subsection{Determine sensitivity of habitats to pressures (Step 3)}

The outcome of Step 1 (reported in full in Section 3.1 below) identified fishing activity and aggregate extraction as important pressures that could affect the case study site under different management scenarios.

An existing matrix classifying the sensitivity of seabed habitats to benthic trawling at different levels of fishing intensity (Hall et al., 2008, some details of which can also be found in Eno et al., 2013) was used as the basis for the assessment of fishing pressure. This required the NDBR habitats to be further grouped into four broad categories at a lower (less resolved) EUNIS level in order to match the categories used within the sensitivity matrix. Utilising this matrix also required knowledge of the fishing activity within the case study site, which was obtained using the vessel density maps resulting from the participatory FisherMap process undertaken by the Finding Sanctuary project (des Clers et al., 2008).

A comparable assessment of the sensitivity of the habitats to aggregate extraction was not found within the literature, so this was inferred from published studies of the recovery times for biota following the cessation of aggregate dredging (Foden et al., 2009; Cooper et al., 2007; Desprez, 
2000). A low sensitivity was assumed for recovery times of less than two years, moderate for two to four years, and high for greater than four years. This assessment focused on the resilience aspect of sensitivity, i.e. the ability of the habitat to recover after an impact. The other component of sensitivity, resistance (the capacity of the habitat to withstand impacts) was expected to be low across all habitats, because the extractive nature of the activity results in the complete removal of significant quantities of the substrate and its associated fauna (Boyd and Rees, 2003), and thus would not affect the relative scores given.

\subsection{Determine the potential for ES delivery by the habitats (Step 4)}

Nursery habitat, waste remediation and carbon sequestration were identified in Step 1 as the ES of most interest to stakeholders (see Section 3.1, below).

A qualitative approach was taken, where ES provision was described using a four point scale (Significant, Moderate, Low, Negligible) after Potts et al. (2014). These levels were relative within each ecosystem service. For nursery habitat and carbon sequestration, the potential of each biotope found in the case study area to deliver the ES was determined using a literature review (see Sections 2.5.1 and 2.5.2 below) while Community Bioturbation Potential was calculated as a proxy for waste remediation (Section 2.5.3).

The outcome for each ecosystem service was also given a confidence score on a three point scale (again following Potts et al., 2014), reflecting the quantity and quality of the information sources used. The confidence scores were defined as High (3): supported by a good body of evidence that is primarily UK-related, peer-reviewed literature; Moderate (2): supported by a fair body of evidence that may be primarily grey or overseas literature; Low (1): supported by a small body of literature or reliant on expert opinion or untested methods. The confidence score was applied to the service as a whole, rather than individual confidence scores being determined for each service in each habitat (as in Potts et al., 2014).

\subsubsection{Nursery habitat}

The potential for each habitat to act as a nursery area was based on sediment type, as there was insufficient published information available to resolve this at the level of the specific biotopes. The likely service delivery was scored on binary scale, reflecting likelihood that biotope had a "significant" or "low" potential to act as a nursery habitat based on the presence of appropriate sediment types. Insufficient information was available to score the habitats on a more expansive relative scale. 


\subsubsection{Carbon Sequestration}

Few empirical studies exist that quantify rates of sequestration of carbon by different subtidal sedimentary habitats. Therefore, the potential for the biotopes to provide this service was based on the availability of mud within the sediment, an assumption based on the known relationship between smaller sediment grain sizes and increased concentrations of total organic carbon (de Falco et al., 2004; McBreen et al., 2008; Serpetti et al., 2012) and the limited capacity of coarse sediments to store carbon resulting from the rapid processing of biomass (Alonso et al., 2012). Site specific biomass has been used as indicator of carbon sequestration (Austen et al., 2009; Cooper et al., 2013), and the feeding and burrowing behaviours of benthic fauna are likely to have an effect on the rates of carbon burial. However, these changes will be relatively minor compared to the differences between vegetated and non-vegetated habitats, and so were not considered likely to affect the broad categorisation used in this study.

\subsubsection{Waste Remediation}

Waste remediation has been defined as "the removal of pollutants through storage, burial and recycling" (Beaumont et al., 2007). As with carbon sequestration, the capacity of a habitat to reduce the potential harmful impact of pollutant inputs is rarely measured directly. Therefore, an indicator had to be selected that would reflect the likely potential of the species within a particular biotope to perform this service. The indicator used was community bioturbation potential (BPc). Bioturbation (the mixing of sediments during biological activity) influences a very wide range of ecosystem processes including oxygen gradients, bacterial activity and nutrient cycling (Queirós et al., 2013) which in turn influence how waste materials entering the system can be remediated. BPc is becoming increasingly used as an indicator of seabed integrity and function (Painting et al., 2013; Birchenough et al., 2012), supporting its use here as a proxy for the ability of the habitat to process waste material.

BPc was calculated following Queirós et al. (2013), using species size and abundance data from benthic sampling that had taken place across the NBDR (RWE npower, 2011; Mackie et al, 2006; Warwick and Davies, 1977) and averaged across the samples for each biotope. The BPc score obtained was rescaled using log transformation to facilitate conversion to a three-point scale for waste remediation potential, where three (or less) equated to a low level, four to a moderate level and five to a high level.

\subsection{Determine sensitivity of ES to changes in pressure (Step 5)}

The final stage of the process was to determine whether the sensitivity attributed to the habitat remained appropriate at the level of the individual ES. Further reference to available literature supported by expert judgement was used to consider the attributes of the habitat that were responsible for the delivery of the different ES and their likely response to the pressures. This evaluation 
concerned the both issues of direct loss of key species responsible for providing the service as a result of human activity, and indirect effects on these species such as changes in prey availability or the reduction of habitat complexity.

This sensitivity assessment was extended to incorporate information about the supply of the ES, and hence increase its usefulness for management purposes: where the supply of a service is negligible, impacts on its delivery will have little actual effect even where it is classified as highly sensitive to the pressure The sensitivity of the service to the different pressures was therefore combined with the level of ES provision (Step 4) to indicate which biotopes or ES could be of particular management concern. This was scored in order to indicate a continuum of potential risk (with darkening shading representing increasing risk, Table 1). Attempts should not be made to interpret this scoring as a series of discrete levels, for which greater quantification and certainty with regard to the underlying data would be required.

Table 1. A matrix for scoring the continuum of risk (with darkening shading representing increasing risk) to the delivery of ES resulting from the combination of level of service provision with ES sensitivity

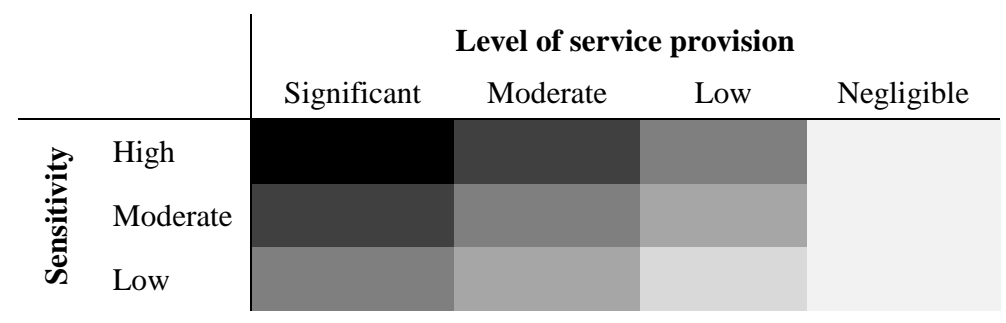

\section{Results}

\subsection{Key ES and management issues}

The supply of ES by subtidal sedimentary habitats was of most interest to the stakeholders interviewed, particularly in terms of nursery habitat for commercial species, waste remediation and carbon sequestration (the capture and long term storage of atmospheric carbon dioxide). Six species or groups of species of particular commercial importance locally were identified: bass (Dicentrarchus labrax), lobster (Homarus gammarus), rays (Rajidae), cod (Gadus morhua), plaice (Pleuronectes platessa) and sole (Solea solea), which together contributed $60 \%$ of the total value of landings from the relevant ICES rectangle during the period 1990 to 2013 (MMO, unpublished data).The scenario process undertaken with the stakeholders identified two key pressures that would change under future scenarios and required further investigation: fishing intensity and aggregate extraction. 


\subsection{Habitat types}

Six overarching habitat types comprising ten individual EUNIS habitats were identified within the NDBR(Figure 3), including mud, sands and coarser sediments (in addition to rock, which did not form part of the assessment).

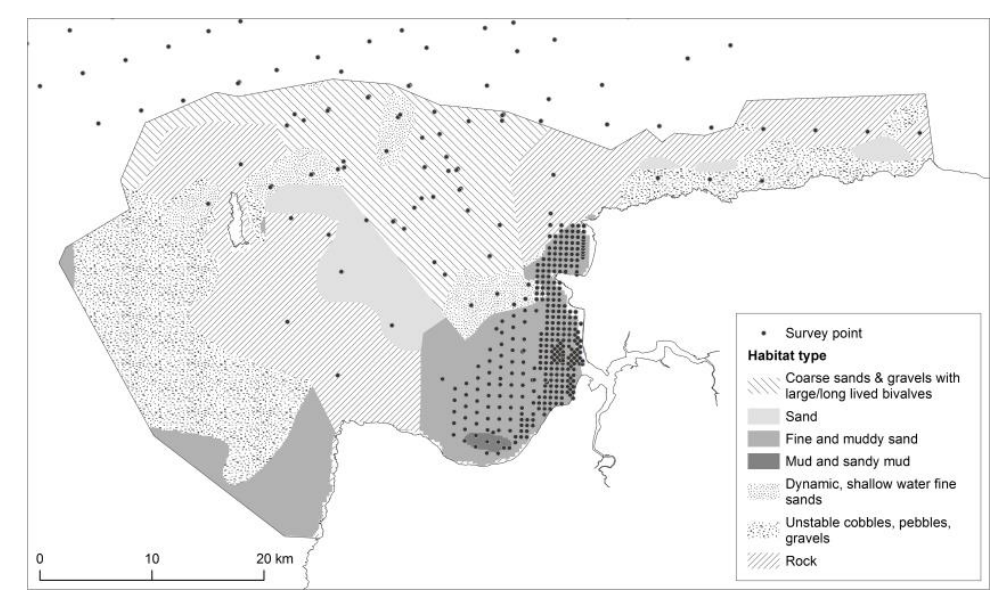

Figure 3. The habitats within the case study site, including the location of sampling points used during benthic surveys in the area

\subsection{Habitat sensitivity}

Across much of the NDBR, demersal trawling is undertaken by less than three vessels in a given month, although parts of Bideford Bay can be exposed to trawling by up to five vessels during the autumn and winter (des Clers et al., 2008). The current levels of intensity were therefore judged to be low or moderate in different parts of the site (defined by Hall et al. (2008) as the typical levels of commercial fishing by part-time and full-time fishers respectively). All habitats within the NDBR were at least moderately sensitive to moderate trawling intensity, but this was reduced to low sensitivity under low trawling pressure (Table 2). The coarse sand habitats with bivalve communities were most sensitive, to both trawling and aggregate extraction.

Table 2. The sensitivity of selected subtidal sedimentary habitats to demersal trawling and aggregate extraction

\begin{tabular}{|l|l|l|l|}
\hline & $\begin{array}{c}\text { Demersal } \\
\text { trawling: } \\
\text { moderate }\end{array}$ & $\begin{array}{c}\text { Demersal } \\
\text { trawling: } \\
\text { low }\end{array}$ & $\begin{array}{c}\text { Aggregate } \\
\text { extraction }\end{array}$ \\
\hline Coarse sands and gravels with large/long lived bivalves & & & \\
\hline Subtidal stable muddy sands, sandy muds and muds & & & \\
\hline Dynamic, shallow water fine sands & & & \\
\hline Unstable cobbles, pebbles, gravels & & & \\
\hline \\
Sensitivity of habitat to pressure: $\square$ High $\square$ Moderate $\square$ Low $\square$ Activity unlikely to occur
\end{tabular}




\subsection{Potential ES delivery by the habitats}

\subsubsection{Nursery habitat}

Sole and plaice are comparatively well-studied species, and have very similar preferences in their selection of estuarine and sheltered coastal areas as nursery habitats. Laboratory and field experiments have demonstrated a preference for mud and fine sand substrates (Le Pape et al., 2003; Cabral and Costa, 1999; Martinho et al., 2007; Eastwood et al., 2003; Gibson and Robb, 2000; Lauria et al. 2011; Poxton and Nasir, 1985; de Raedmaecker et al, 2012) and water less than 20m deep (Le Pape et al., 2003; Rogers et al., 1998; Eastwood et al., 2003; Lauria et al. 2011; de Raedmaecker et al, 2012). Juvenile bass also show a preference for habitats with mud or sand substrates (Vasconcelos et al., 2010; Martinho et al., 2007; Kelley 1998), and for shallow waters, often with depths less than 5m (Rogers et al., 1998; Martinho et al., 2007).

Juvenile cod prefer coarse substrates such as gravel, pebble, cobble and rock, may associate with maerl or eelgrass beds (Lough et al., 1989; Kamenos et al., 2004; Warren et al., 2009., Gotceitas et al., 1997), and appear not be restricted to shallow areas, having been observed at depths in excess of $70 \mathrm{~m}$ (Lough et al., 1989; Nielsen et al., 2013). Early benthic phase lobsters dig burrows into mud or seek shelter in gravel or cobble habitats, showing a particular preference for the latter when predatory pressure is high (Howard and Bennett, 1979; Cobb and Wahle, 1994; Linnane et al. 2000; Ball et al. 2001).

Rays were included as a group because the collection of fishery data resolved species level had only recently been implemented. Unfortunately, the group exhibits a wide habitat preference, which masks any distinctions between individual species. There are indications that rays use shallow sheltered areas as nursery habitats (Walker et al., 1997), usually preferring depths less than 20m (Rogers et al., 1998) although juvenile rays have been caught from fishing grounds where the water depth exceeds 100m (Serra-Periera et al., 2014). There is some evidence that juvenile rays favour sand, gravel and rock substrates (Serra-Periera et al., 2014), although they may also associate with more muddy areas (Rousset et al. 2009).

\subsubsection{Carbon Sequestration}

The potential for the subtidal sedimentary habitats in the NDBR to sequester carbon was scored on a binary scale, of "low" where mud was present or "negligible" in its absence, reflecting that these habitats are unlikely to provide the same level of service delivery as vegetated biotopes such as seagrass or saltmarsh. This assumption is based on the relative sequestration rates of saltmarsh compared to other vegetated coastal margin habitats and to intertidal mudflats (Beaumont et al., 2014; Andrews et al., 2006). The levels of organic carbon buried in intertidal mudflats seaward of mangrove forests have been shown to be substantial (Sanders et al., 2010). However, comparable measurements 
for sedimentary habitats which lack the presence of significant coastal vegetation were not found, and so there is no basis for assuming that that the subtidal habitats of the NBDR provide a significant level of carbon sequestration.

\subsubsection{Waste Remediation}

There was a good level of consistency in BPc between different samples of each substrate type, with low standard errors. No subtidal biotopes scored highly, although this score was recorded for additional samples taken from intertidal habitats within the local Taw Torridge estuary, suggesting that the scale remains appropriate. Unfortunately, field data were not available for all the biotopes reported for the NDBR, as some of these were derived from models. In the absence of information on the biota, the BPc values could not be calculated and so it was not possible to derive a waste remediation score.

\subsubsection{Summary}

In summary, the potential for the subtidal sedimentary habitats of the NDBR to deliver the regulating ES of interest was often low, reflecting the lack of vegetated habitats and the relatively low BPc scores (Table 3). All the biotopes provided potential nursery habitat for at least one commercially important species. The mud and sandy mud found inshore in Bideford Bay is likely to be the most important for juvenile lobster and also has the potential to support juveniles of all species except cod. More suitable habitat for the latter (as well as for skates and rays) is likely to be provided by the coarser substrates found to the north and west of the area. Mud and sandy mud also provided the higher levels of carbon sequestration potential (although still at a low level), while the presence of large bivalves resulted in a moderate waste remediation score. 
Table 3. The contribution of different subtidal sedimentary habitats to the provision of marine ecosystem services, scored following the scale of Potts et al. (2014). Habitat categories are derived from Hall et al. (2008).

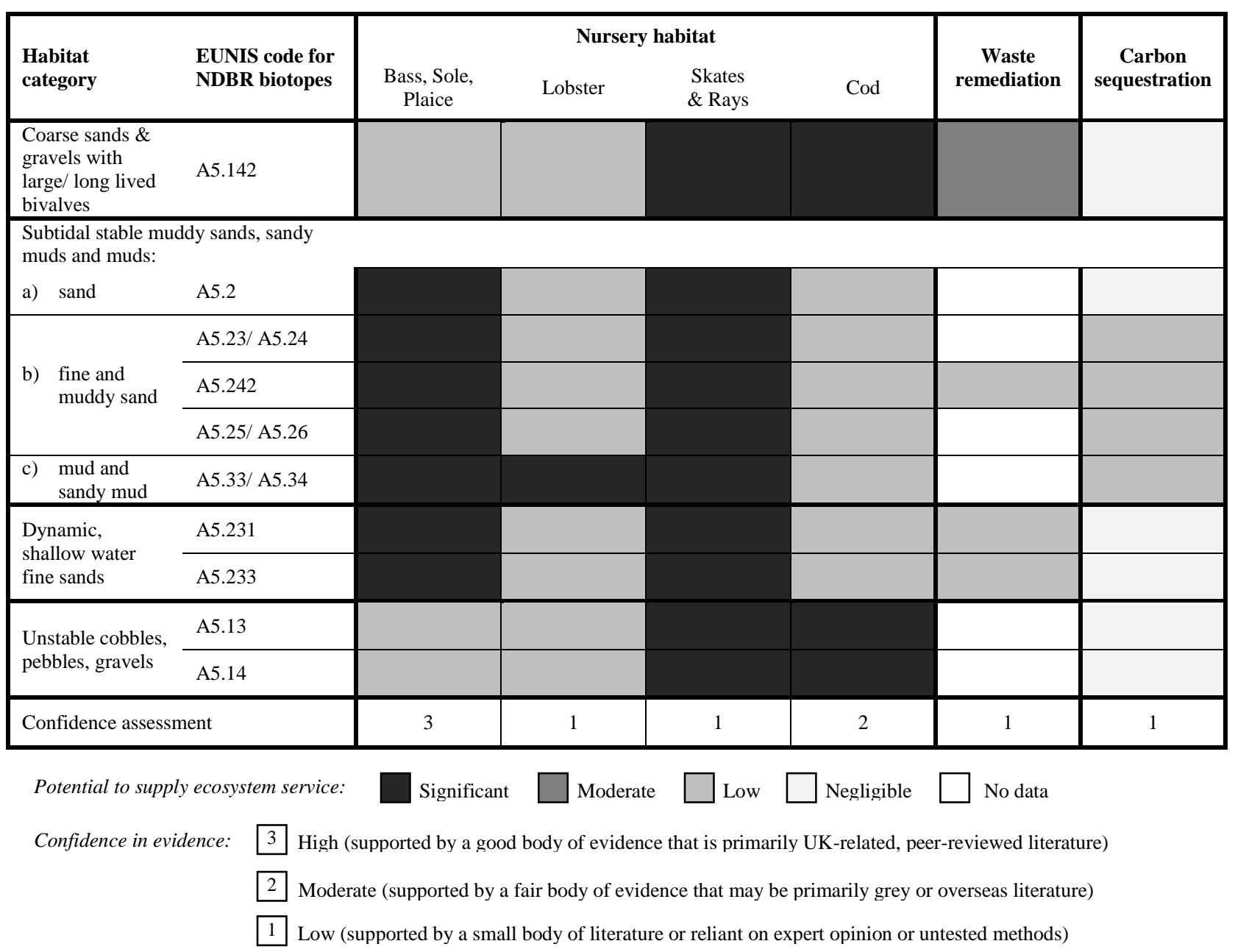

\subsection{ES sensitivity under changing pressure}

The presence of fisheries using towed bottom gears is expected to affect the nursery function of the habitat because juvenile individuals may be taken directly, particularly where mixed species fisheries occur: Fishery closures such as the Plaice Box have been established to reduce the bycatch of juveniles in heavily trawled areas (Hiddink et al., 2007a). Bottom trawling will also affect the complexity of the habitat by flattening wave forms, and removing rock, shell fragments, biogenic reefs and other structural organisms (Kaiser et al., 2003; Handley et al., 2014), thus reducing the available shelter. Changes to benthic communities will also affect food availability, although in some cases (such as for plaice) this change may be to the benefit of the juvenile fish by increasing the abundance of small polychaetes (Hiddink et al., 2007a).

Aggregate extraction results in the removal of sediments and the associated fauna, causing significant reductions in species diversity, richness and biomass (Desprez, 2000; Boyd and Rees, 2003). The direct impacts on fish nursery habitat appear to be poorly studied (although brief reference is made to this issue within Cooper et al., 2013). However, it can be assumed that the potential effects of 
aggregate extraction include changes in prey availability, increased vulnerability to predators due to higher water turbidity, and elevated exposure to contaminants in re-suspended sediments (Stelzenmüller et al., 2010) which are likely to reduce the suitability of the area as a nursery habitat.

The carbon sequestration potential of the habitat is sensitive to seabed disturbance, as any process that affects infauna and sediment mixing will alter carbon storage (Alonso et al., 2012). The upward movement of sediments caused by activities such as trawling is likely to be a factor in reducing carbon burial (Alongi et al., 2007), and modelling suggests that trawling in sheltered soft sediments can cause dramatic fluctuations in the partitioning of carbon within the sediment (Duplisea et al., 2001). Aggregate extraction results in an increased proportion of fine sediment due to the removal of the coarser grains (Desprez, 2000), and as such the potential of the habitat to sequester carbon may ultimately be increased (Alonso et al., 2012). However, the ongoing disturbance of the habitat during the active phase of the sediment extraction is unlikely to be conducive to carbon burial.

The community bioturbation potential (BPc) used as an indicator for waste remediation is a function of the benthic biota. The sensitivity of waste remediation as measured by this indicator therefore depends on how functional traits within the benthic community might be changed by the pressures on the habitat. The larger fauna usually make a significant contribution to bioturbation (Duplisea, 2001), with the NDBR data suggesting that the presence of large bivalves is key to increased BPc and hence higher levels of waste remediation. Trawling removes bioturbators (Duplisea, 2001) and so is likely to reduce the potential of the habitat to remediate waste. The negative effects of aggregate extraction on species diversity, richness and biomass (Desprez, 2000; Boyd and Rees, 2003) are also likely to reduce bioturbation and hence waste processing potential. Trawling and aggregate extraction also cause the re-suspension of sediments, and the release of nutrients and contaminants back into the water column (Kaiser et al., 2003; Austen et al., 2009), potentially increasing the levels of waste materials in the local environment.

This evidence suggests that trawling and aggregate extraction are likely to have predominantly negative effects on all of the ES considered, suggesting that the level of sensitivity to these pressures allocated for the habitats (Table 3) remains an appropriate measure for the sensitivity of the service. The potential benefit to juvenile plaice from trawling disturbance was notable as a positive effect on nursery habitat provision, and provides an example of a situation in which different factors of the overall supply of ES may be affected in different directions. However, as plaice was not the only species within this category, and the available evidence was not sufficient to suggest that this benefit outweighed negative impacts, a precautionary approach was taken to maintain the sensitivity of the ES provision as that of the habitats more broadly (generally low to moderate, depending on the intensity of the trawling effort). 
The combination of the ES sensitivity assessment with the level of service provision indicates that the potential for coarse sand and gravels (EUNIS A5.142) to provide nursery habitat and waste remediation may be at risk from trawling and aggregate extraction (Table 4). The higher levels of trawling may also put at moderate risk the continued supply of nursery habitat for bass, sole, plaice, skates and rays. Conversely, the negligible level of carbon sequestration in coarse substrates leads to a low risk score, suggesting that management efforts to maintain and enhance this service may be better focused elsewhere.

Table 4. The continuum of risk to the delivery of ES resulting from the combination of level of service provision with ES sensitivity for selected subtidal sedimentary habitats to demersal trawling (Tra) (at moderate (M) and low (L) fishing intensity) and to aggregate extraction (Ag). Habitat categories are derived from Hall et al. (2008).

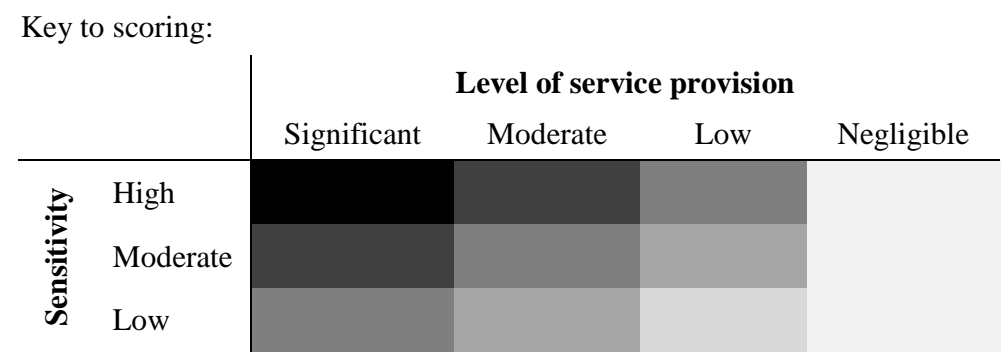

Activity unlikely to occur, or data on service provision unavailable

\begin{tabular}{|c|c|c|c|c|c|c|c|c|c|c|c|c|c|c|c|}
\hline \multirow[b]{4}{*}{ Habitat category } & \multirow{4}{*}{$\begin{array}{l}\text { EUNIS } \\
\text { code for } \\
\text { NDBR } \\
\text { biotopes }\end{array}$} & \multicolumn{10}{|c|}{ Nursery habitat } & \multirow{2}{*}{\multicolumn{2}{|c|}{$\begin{array}{l}\text { Waste } \\
\text { remediation }\end{array}$}} & \multirow{2}{*}{\multicolumn{2}{|c|}{$\begin{array}{c}\text { Carbon } \\
\text { sequestration }\end{array}$}} \\
\hline & & \multicolumn{3}{|c|}{$\begin{array}{l}\text { Bass, Sole, } \\
\text { Plaice }\end{array}$} & \multicolumn{2}{|c|}{ Lobster } & \multicolumn{2}{|c|}{$\begin{array}{l}\text { Skates } \\
\& \text { Rays }\end{array}$} & \multicolumn{3}{|c|}{ Cod } & & & & \\
\hline & & \multicolumn{2}{|c|}{ Tra } & $\mathrm{Ag}$ & \multicolumn{2}{|l|}{ Tra } & Tra & $\mathrm{Ag}$ & \multicolumn{2}{|c|}{ Tra } & \multirow[t]{2}{*}{$\mathrm{Ag}$} & \multicolumn{2}{|c|}{ Tra $\quad \mathrm{Ag}$} & Tra & $\mathrm{Ag}$ \\
\hline & & & & & M L & & M L & & M & $\mathrm{L}$ & & M L & & M L & \\
\hline $\begin{array}{l}\text { Coarse sands \& } \\
\text { gravels with large/ } \\
\text { long lived } \\
\text { bivalves }\end{array}$ & A5.142 & & & & & & & & & & & & & & \\
\hline \multicolumn{2}{|c|}{$\begin{array}{l}\text { Subtidal stable muddy sands, } \\
\text { sandy muds and muds: }\end{array}$} & & & & & & & & & & & & & & \\
\hline a) sand & A5.2 & & & & & & & & & & & & & & \\
\hline \multirow{3}{*}{$\begin{array}{l}\text { b) fine and } \\
\text { muddy sand }\end{array}$} & $\begin{array}{l}\text { A5.23/ } \\
\text { A5.24 }\end{array}$ & & & & & & & & & & & & & & \\
\hline & A5.242 & & & & & & & & & & & & & & \\
\hline & $\begin{array}{l}\text { A5.25/ } \\
\text { A5.26 }\end{array}$ & & & & & & & & & & & & & & \\
\hline $\begin{array}{l}\text { c) mud and } \\
\text { sandy mud }\end{array}$ & $\begin{array}{l}\text { A5.33/ } \\
\text { A5.34 }\end{array}$ & & & & & & & & & & & & & & \\
\hline \multirow{2}{*}{$\begin{array}{l}\text { Dynamic, shallow } \\
\text { water fine sands }\end{array}$} & A5.231 & & & & & & & & & & & & & & \\
\hline & A5.233 & & & & & & & & & & & & & & \\
\hline \multirow{2}{*}{$\begin{array}{l}\text { Unstable cobbles, } \\
\text { pebbles, gravels }\end{array}$} & A5.13 & & & & & & & & & & & & & & \\
\hline & A5.14 & & & & & & & & & & & & & & \\
\hline
\end{tabular}




\section{Discussion}

This case study demonstrates how existing studies of habitat sensitivity can be usefully incorporated into ES assessments, and that a matrix combining ES provision with sensitivity assessment provides information in an accessible format that can be used to inform management decisions and prioritise actions.

\subsection{Limitations}

Adopting any pre-existing sensitivity assessment will also require adopting the caveats applied to its findings. For example, Hall et al. (2008) make explicit the limitations of their work, which does not take account of: i) how removal of target species affects the habitat (for example the implications of removing certain fish from around kelp beds); ii) any seasonal variation in fishing intensity and habitat recovery; or iii) the cumulative impacts of multiple fishing gear types. Similarly, Potts et al. (2014) also note that it is more challenging to assess the ecosystem service provision by broadscale habitats (and lower confidence tends to result) than for specific habitat features. Coupling the limitations of the sensitivity assessment with those associated with determining the relationships between ES and habitats means that the uncertainty may be considerable. However, provided this is transparent and clearly communicated, it does not diminish the value of the approach, and the findings were well received by the NDBR stakeholders.

\subsection{Recommendations and data gaps}

In this case study, the links between the habitats and the ES provided, and also how the ES might change with changing intensity of pressures, were based on existing literature, which was not extensive. It is often stated that there is a need for improved understanding of the role of particular species and habitats in the delivery of ES (e.g. Townsend et al., 2013). The availability of detailed information would increase the confidence in ES sensitivity assessment. The work reported here would have been improved by the availability of more data on the rates of carbon sequestration by subtidal sediments and by defined indicators for waste remediation services (and/or an empirical assessment of the suitability of community bioturbation potential for this purpose). The availability of additional data would also permit a less qualitative approach, addressing criticisms that sensitivity assessments based on expert judgement and/or scoring are neither validated, quantifiable nor repeatable (Hiddink et al., 2007b). For example, a statistical modelling approach has been proposed to assess ES sensitivity to land use change for subalpine grasslands, where the links between plant traits/functional types and ES are sufficiently well understood (Quétier et al., 2007). This approach is transferable to the marine environment, although the linkages between species traits and ecosystem services may be less well understood. Further empirical research including the evaluation of appropriate indicators (such as, for example, determining the relationship between Community 
Bioturbation Potential and both waste remediation and carbon sequestration) would allow such ES modelling approaches to be developed.

Also, a better understanding of the response of the ES themselves to changes in pressure is required: even with considerable changes in species abundance or diversity it remains possible that a particular ES may continue to be delivered. For example, between 2001 and 2004, there were substantial changes in the catches of particular species landed from the NDBR area including a doubling of bass landings, a decline of $85 \%$ in cod catches and a nearly twentyfold increase in whelk. However, in both years, about 1,300 tonnes of fish and shellfish was landed, indicating that food provision remained constant and thus the ES does not have the same sensitivity to changes in drivers and pressures as the individual species. Similarly, benthic communities with a very similar bioturbation potential (and hence waste remediation score) can comprise very different species. For example, a community dominated by the venerid bivalve Spisula elliptica could be replaced by one in which the polychaete Lumbrineris gracilis is most abundant, without substantially impacting the potential for waste remediation as measured by BPc.

\subsection{Using ES Assessment in a management context}

ES assessment should support decision-making rather than serving as a standalone decision-making tool, and it is essential that the wider context is understood before decisions can be made. It is also important to consider the widest possible range of ES, as this increases the likelihood that all ES gains and losses from environmental change will be appropriately accounted for. For example, while one species may substitute for another in terms of food provision, it may not do so for other services, such as habitat engineering, waste remediation or cultural significance, where other specific characteristics of the species are fundamental to provision of the ES. Therefore, an assessment considering a greater range of ES will more adequately demonstrate the wider consequences of changes in populations. Likewise, understanding who benefits or loses from any change in ES provision is also key to understanding the true societal consequences of a given change in pressure. The methodology presented here has potential to frame pressures in term of their societal relevance, thus enabling stakeholders to have a more holistic understanding of the potential impact of pressures on their local ecosystem. Linking pressures to tangible impacts on ES, and in turn on societal and economic wellbeing, is critical when managing ecosystems for a variety of uses. It is only through increasing our understanding of these linkages that managers can see clearly the trade-offs associated with human activity in the environment, and develop strategies accordingly. It is hoped that the development of transferable methodologies, as presented here, will increase transparency on the broader impacts of pressures on the environment. 


\section{Conclusion}

This research has demonstrated that it is possible to extend the concept of sensitivity assessment to ES. Existing sensitivity assessments for the underlying habitats and species are an appropriate foundation, where the linkages between these habitats and species and the ES in question are relatively well understood. However, this understanding is generally not well developed; additional empirical research would increase confidence, allow a wider range of ES to be considered and reduce the risk of the socio-economic consequences of ES supply being masked by the potential for substitution between species or habitats. Consequently, the approach has the potential to be limited by a lack of empirical data and uncertainty arising from these limitations should be clearly acknowledged and ideally should provide the basis for the future ES research agenda.

In conclusion, the methodology presented provides a novel and transferable framework for assessing how pressures impact ES, which can be used to inform management decisions and highlight management priorities for intervention to ensure ES provision is maintained. In doing so, the approach supports blue growth and sustainable development in the marine and maritime sectors that rely on living resources.

\section{Acknowledgments}

This work was carried out as part of the VALMER project, which was supported by the European cross-border cooperation programme INTERREG IV A France (Channel) England, co-funded by the ERDF. Additional support was provided through the Natural Environment Research Council and Department for Environment, Food and Rural Affairs [grant number NE/L003279/1, Marine Ecosystems Research Programme]. Our thanks also go to Harvey Tyler-Walters at the Marine Biological Association for supporting our understanding of the sensitivity assessment process.

\section{Highlights}

- A novel framework to assess how pressures effect ecosystem services is presented.

- The concept of sensitivity assessment is extended to consider specific services.

- Incorporating sensitivity increases the usefulness of ecosystem service assessment.

\section{References}

ABPmer. 2010. Cowes Outer Harbour Project Environmental Impact Assessment. June 2009 (updated April 2010). Project ref: R/3752/5. Report no: R.1518. Prepared for the South East of England Development Agency and Cowes Harbour Commission. 
Alongi D.M., Trott L.A and Pfitzner J. 2007. Deposition, mineralization, and storage of carbon and nitrogen in sediments of the far northern and northern Great Barrier Reef shelf. Continental Shelf Research 27: 2592-2622

Alonso I., Weston K., Gregg R. and Morecroft M. 2012. Carbon storage by habitat - Review of the evidence of the impacts of management decisions and condition on carbon stores and sources. Natural England Research Reports, Number NERR043.

Andrews J.E., Burgess D., Cave R.R., Coombes E.G., Jickells T.D., Parkes D.J. and Turner R.K.. 2006. Biogeochemical value of managed realignment, Humber estuary, UK. Science of the Total Environment 371: 19-30

Austen M.C., Hattam C., Lowe S., Mangi S.C. and Richardson K. 2009. Quantifying and Valuing the impacts of marine aggregate extraction on ecosystem goods and services. Marine Aggregate Levy Sustainability Fund (MALSF). MEPF 08-P77. 72pp

Ball, B., Linnane, A., Munday, B., Browne, R. and Mercer, J.P., 2001. The effect of cover on in situ predation in early benthic phase European lobster Homarus gammarus. Journal of the Marine Biological Association of the UK, 81(04): pp.639-642.

Beaumont N.J., Jones L., Garbutt A., Hansom J.D. and Toberman M. 2014. The value of carbon sequestration and storage in coastal habitats. Estuarine, Coastal and Shelf Science 137: 32-40

Beaumont N.J, Austen M.C, Atkins J.P, Burdon D, Degraer S, Dentinho T.P, Derous S, Holm P, Horton T, van Ierland E, Marboe A. H, Starkey D.J, Townsend M, and Zarzycki T. 2007. Identification, definition and quantification of goods and services provided by marine biodiversity: Implications for the ecosystem approach. Marine Pollution Bulletin 54: 253-265

Birchenough S.N.R., Parker R.E., McManus E. and Barry J. 2012. Combining bioturbation and redox metrics: Potential tools for assessing seabed function. Ecological Indicators 12: 8-16

Börger T., Beaumont N. J., Pendleton L., Boyle K. J., Cooper P., Fletcher S., Haab T., Hanemann M., Hooper T., Hussain S.S., Portela R., Stithou M, Stockhill J., Taylor T., and Austen, M. C. (2014). Incorporating ecosystem services in marine planning: The role of valuation. Marine Policy 46: 161-170.

Boyd S.E. and Rees H.L. 2003. An examination of the spatial scale of impact on the marine benthos arising from marine aggregate extraction in the central English Channel. Estuarine Coastal and Shelf Science 57(1-2): 1-16

Cabral H. and Costa M.J 1999. Differential Use of Nursery Areas Within the Tagus Estuary by Sympatric Soles, Solea solea and Solea senegalensis. Environmental Biology of Fishes 56(4): 389397 
des Clers, S., Lewin, S., Edwards, D., Searle, S., Lieberknecht, L. and Murphy, D. 2008. FisherMap. Mapping the Grounds: recording fishermen's use of the seas. Final Report. A report published for the Finding Sanctuary project.62pp

Cobb, J.S. and Wahle, R.A. (1994) Early Life History and Recruitment Processes of Clawed Lobsters Crustaceana 67(1):1-25

Cooper, K., Burdon, D., Atkins, J.P., Weiss, L., Somerfield, P., Elliott, M., Turner, K., Ware, S. and Vivian, C. (2013) Can the benefits of physical seabed restoration justify the costs? An assessment of a disused aggregate extraction site off the Thames Estuary, UK. Marine Pollution Bulletin, 75(1): 3345 .

Cooper K., Boyd S., Eggleton J., Limpenny D., Rees H. and Vanstaen K. 2007. Recovery of the seabed following marine aggregate dredging on the Hastings Shingle Bank off the southeast coast of England. Estuarine, Coastal and Shelf Science 75: 547-558

Desprez M. 2000. Physical and biological impact of marine aggregate extraction along the French coast of the Eastern English Channel: short and long-term post-dredging restoration. ICES Journal of Marine Science 57: 1428-1438

Duplisea D.E., Jennings S., Malcolm S.J., Parker R. and Sivyer D. 2001. Modelling potential impacts of bottom trawl fisheries on soft sediment biogeochemistry in the North Sea. Geochemical Transactions 14: 1-6

Eastwood P.D., Meaden G.J., Carpentier A. and Rogers S.I. 2003. Estimating limits to the spatial extent and suitability of sole (Solea solea) nursery grounds in the Dover Strait. Journal of Sea Research 50: 151- 165

Eno, N.C., Frid, C.L.J., Hall, K., Ramsey, K., Sharp, R.A.M., Brazier, D.P., Hearn, S., Dernie, K.M., Robinson, K.A., Paramor, O.A.L. and Robinson, L.A. 2013. Managing the habitat effects of fishing: From seabed maps to sensitivity maps. Journal of Fish Biology 83, 826-846

De Falco, G., Magni, P., Teräsvuori, L.M.H. and Matteucci, G., 2004. Sediment grain size and organic carbon distribution in the Cabras lagoon (Sardinia, western Mediterranean). Chemistry and Ecology, 20(sup1), pp.367-377

Foden J., Rogers S.I. and Jones A.P. 2009. Recovery rates of UK seabed habitats after cessation of aggregate extraction. Marine Ecology Progress Series 390: 15-26

Gibson R.N. and Robb L. 2000. Sediment selection in juvenile plaice and its behavioural basis. Journal of Fish Biology 56: 1258-1275

Gotceitas V., Fraser S. and Brown J.A. 1997. Use of eelgrass beds (Zostera marina) by juvenile Atlantic cod (Gadus morhua). Canadian Journal of Fisheries and Aquatic Sciences 54: 1306-1319 
Hall, K., Paramor, O.A.L., Robinson L.A., Winrow-Giffin, A., Frid C.L.J., Eno, N.C., Dernie, K.M., Sharp, R.A.M., Wyn, G.C. and Ramsay, K. 2008. Mapping the sensitivity of benthic habitats to fishing in Welsh waters - development of a protocol. CCW [Policy Research] Report No: [8/12], $85 \mathrm{pp}$.

Handley, S.J., Willis, T.J., Cole, R.G., Bradley, A., Cairney, D.J., Brown, S.N. and Carter, M.E., 2014. The importance of benchmarking habitat structure and composition for understanding the extent of fishing impacts in soft sediment ecosystems. Journal of Sea Research, 86, pp.58-68.

Hiddink J.G., Rijnsdorp A.D. and Piet G. 2007a. Can bottom trawling disturbance increase food production for a commercial fish species? Canadian Journal of Fisheries and Aquatic Sciences 65: $1393-1401$

Hiddink, J. G., Jennings, S., \& Kaiser, M. J. 2007b. Assessing and predicting the relative ecological impacts of disturbance on habitats with different sensitivities. Journal of Applied Ecology, 44(2), 405-413.

Hiscock K. and Tyler-Walters H. 2006. Assessing the sensitivity of seabed species and biotopes - the Marine Life Information Network (MarLIN ). Hydrobiologia 555:309-320

Howard, A.E. and Bennett, D.B. 1979. The substrate preference and burrowing behaviour of juvenile lobsters (Homarus gammarus (L.)). Journal of Natural History 13:4: 433-438

JNCC. 2013. MESH Predicted broad-scale EUNIS habitats - Atlantic Area.

JNCC. 2010. EUSeaMap Atlantic Habitats.

Kaiser M.J., Collie J.S., Hall S.J., Jennings S. and Poiner I.R. 2003. Impacts of Fishing Gear on Marine Benthic Habitats. In Sinclair M. and Valdimarsson G. (Eds). Responsible Fisheries in the Marine Ecosystem. CABI publishing and FAO.

Kamenos N.A., Moore P.G. and Hall-Spencer J.M. 2004. Small-scale distribution of juvenile gadoids in shallow inshore waters; what role does maerl play? ICES Journal of Marine Science 61: $422-$ 429

Kelley D.F. 1998. The importance of estuaries for sea-bass, Dicentrarchus labrax. Journal of Fish Biology 33 (A): 25-33

Langmead O., Hooper T., Griffiths C., Beaumont N. and Guilbert S. 2015. Chapter 3 - Case study process: North Devon. In: Dodds W. and Friedrich L.A. (Eds.). The potential role of ecosystem service assessment in marine governance in the western Channel. VALMER Work Package 4 evidence base report. VALMER project.

Lauria V., Vaz S., Martin C.S., Mackinson S. and Carpentier A. 2011. What influences European plaice (Pleuronectes platessa) distribution in the eastern English Channel? Using habitat 
modelling and GIS to predict habitat utilization. ICES Journal of Marine Science 68(7): 15001510

Le Pape O., Chauvet F., Mahévas S., Lazure P, Guérault D. and Désaunay Y. 2003. Quantitative description of habitat suitability for the juvenile common sole (Solea solea, L.) in the Bay of Biscay (France) and the contribution of different habitats to the adult population. Journal of Sea Research 50: 139-149

Linnane, A., Mazzoni, D. and Mercer, J.P. 2000. A long-term mesocosm study on the settlement and survival of juvenile European lobster Homarus gammarus L. in four natural substrata. Journal of Experimental Marine Biology and Ecology 249: 51-64

Lough R.G., Valentine P.C., Potter D.C., Auditore P.J., Bolz G.R., Neilson J.D., and Perry I. 1989. Ecology and distribution of juvenile cod and haddock in relation to sediment type and bottom currents on eastern Georges Bank. Marine Ecology Progress Series 56: 1-12

Mackie, A. S. Y., James, J. W. C., Rees, E. I. S., Darbyshire, T., Philpott, S. L., Mortimer, K., Jenkins, G. O. and Morando, A. 2006. The Outer Bristol Channel Marine Habitat Study. — Studies in Marine Biodiversity and Systematics from the National Museum of Wales. BIOMÔR Reports 4: 249 pp. \& Appendix 228 pp.

Mainwaring, K., Tillin, H. and Tyler-Walters, H., 2014. Assessing the sensitivity of blue mussels (Mytilus edulis) to pressures associated with human activities JNCC Report No: 506.

Martinho F., Leitão R., Neto J.M., Cabral H.N., Marques J.C. and Pardal M.A. 2007. The use of nursery areas by juvenile fish in a temperate estuary, Portugal. Hydrobiologia 587:281-290

McBreen F., Wilson J.G., Mackie A.S.Y. and Nic Aonghusa C. 2008. Seabed mapping in the southern Irish Sea: predicting benthic biological communities based on sediment characteristics.

Hydrobiologia 606:93-103

MAES. 2013. Mapping and Assessment of Ecosystems and their Services. An analytical framework for ecosystem assessments under action 5 of the EU biodiversity strategy to 2020. Discussion paper - Final, April 2013. Technical Report - 2103 - 067. Publications office of the European Union, Luxembourg. ISBN 978-92-79-29369-6

MMO. 2012. Chapter 5: Interactions - between multiple activities and between activities and environment. In: MMO. 2012. East Inshore and East Offshore Marine Plan Areas Evidence and Issues Report 2012. p205-232

NCC. 2014. Towards a Framework for Defining and Measuring Changes in Natural Capital. Working Paper 1. March 2014. Natural Capital Committee. 21pp. 
Nielsen, J.R., Lundgren, B., Kristensen, K. and Bastardie, F., 2013. Localisation of nursery areas based on comparative analyses of the horizontal and vertical distribution patterns of juvenile Baltic Cod (Gadus morhua). PloS one, 8(8), p.e70668.

OSPAR. 2003. Criteria for the Identification of Species and Habitats in need of Protection and their Method of Application (The Texel-Faial Criteria). OSPAR Convention for the Protection of the Marine Environment of the North-East Atlantic. Meeting of the OSPAR Commission, Bremen, 2327 June 2003. Reference Number: 2003-13. OSPAR 03/17/1-E, Annex 5

Painting S. J., van der Molen J., Parker E.R., Coughlan C., Birchenough S., Bolam S., Aldridge J.N., Forster R.M. and Greenwood N. 2013. Development of indicators of ecosystem functioning in a temperate shelf sea: a combined fieldwork and modelling approach. Biogeochemistry 113:237-257

Pecl, G.T., Ward, T.M., Doubleday, Z.A., Clarke, S., Day, J., Dixon, C., Frusher, S., Gibbs, P., Hobday, A.J., Hutchinson, N. and Jennings, S., 2014. Rapid assessment of fisheries species sensitivity to climate change. Climatic Change, 127(3-4): 505-520.

Pendleton L., R. Mongruel, N.Beaumont, T. Hooper, M. Charles. A Triage Approach to Improve the Relevance of Marine Ecosystem Services Assessments. Marine Ecology Progress Series (MEPS) 530:183-193. 2015

Potts T., Burdon D., Jackson E., Atkins J., Saunders J., Hastings E. and Langmead, O. 2014. Do marine protected areas deliver flows of ecosystem services to support human welfare? Marine Policy 44:139-148

Poxton M.G. and Nasir N.A. 1985. The distribution and population dynamics of O-group plaice (Pleuronectes platessa L.) on nursery grounds in the Firth of Forth. Estuarine, Coastal and SheIf Science 21:845-857

Queirós A.M., Birchenough S.N.R., Bremner J., Godbold J.A., Parker R.E., Romero-Ramirez A., Reiss H., Solan M., Somerfield P.J., van Colen C., van Hoey G. and Widdicombe S. 2013. A bioturbation classification of European marine infaunal invertebrates. Ecology and Evolution 3(11): 3958-3985

Quétier, F., Lavorel, S., Thuiller, W., \& Davies, I. 2007. Plant-trait-based modeling assessment of ecosystem-service sensitivity to land-use change. Ecological Applications, 17(8), 2377-2386.

De Raedemaecker F., Brophy D., O'Connor I. and Comerford S. 2012. Habitat characteristics promoting high density and condition of juvenile flatfish at nursery grounds on the west coast of Ireland. Journal of Sea Research 73: 7-17

Rogers S. I. Millner R. S. and Mead T. A. 1998. The distribution and abundance of young fish on the east and south coast of England (1981 to 1997). Science Series Technical Report 108. CEFAS, Lowestoft. 130pp. 
Rousset J. 2009. Population structure of Thornback rays Raja clavata and their movements in the Bay of Douarnenez. Journal of the Marine Biological Association UK 70: 261-268

RWE npower. 2011. Atlantic Array Grab Logs, and Atlantic Array Epibenthic Trawl Log. Field data from Atlantic Array environmental survey.

Sanders C.J., Smoak J.M., Naidu A.S., Sanders L.M., and Patchineelam S. R. 2010. Organic carbon burial in a mangrove forest, margin and intertidal mud flat. Estuarine, Coastal and Shelf Science 90: $168-172$

Serpetti N, Heath M., Rose M. and Witte U. 2012. High resolution mapping of sediment organic matter from acoustic reflectance data. Hydrobiologia 680:265-284

Serra-Pereira B., Erzini K., Maia C. and Figueiredo I. 2014. Identification of Potential Essential Fish Habitats for Skates Based on Fishers’ Knowledge. Environmental Management 53(5):985-98

Stelzenmüller V., Ellis J.R., and Rogers S.I. 2010. Towards a spatially explicit risk assessment for marine management: Assessing the vulnerability of fish to aggregate extraction. Biological Conservation 143: 230-238

Tillin, H.M., Hull, S.C., Tyler-Walters, H. 2010. Development of a Sensitivity Matrix (pressuresMCZ/MPA features). Report to the Department of Environment, Food and Rural Affairs from ABPMer, Southampton and the Marine Life Information Network (MarLIN) Plymouth: Marine Biological Association of the UK. .Defra Contract No. MB0102 Task 3A, Report No. 22.

TEEB (2010) The Economics of Ecosystems and Biodiversity: Ecological and Economic Foundations. Kumar, P. (Ed), Earthscan, London and Washington.

Townsend M., Thrush S.F., Lohrer A.M., Hewitt J.E., Lundquist C.J., Carbines M. and Felsing M. 2014. Overcoming the challenges of data scarcity in mapping marine ecosystem service potential Ecosystem Services 8: 44-55

UKNEA. 2011. The UK National Ecosystem Assessment Technical Report. UNEP-WCMC, Cambridge.

Vasconcelos R.P., Reis-Santos P., Maia A., Fonseca V., França S., Wouters N., Costa M.J. and Cabral H.N. 2010. Nursery use patterns of commercially important marine fish species in estuarine systems along the Portuguese coast. Estuarine, Coastal and Shelf Science 86: 613-624

Walker P., Howlett G. and Millner R. 1997. Distribution, movement and stock structure of three ray species in the North Sea and eastern English Channel. ICES Journal of Marine Science 54: 797808

Warren M.A., Gregory R.S., Laurel B.J. and SnelgroveI P.V.R. 2010. Increasing density of juvenile Atlantic (Gadus morhua) and Greenland cod (G. ogac) in association with spatial expansion and 
recovery of eelgrass (Zostera marina) in a coastal nursery habitat. Journal of Experimental Marine Biology and Ecology 394: 154-160

Warwick, R.M. and Davies, J.R., 1977. The distribution of sublittoral macrofauna communities in the Bristol Channel in relation to the substrate. Estuarine and Coastal Marine Science, 5(2): 267-288. 